\title{
ResearchArticle
}

\section{Evaluation of morpho-physiological attributes of Fenugreek (Trigonella foenum graecum) genotypes under different water regimes}

\author{
JYOTI CHAUHAN, BAJRANG LAL KAKRALYA AND RAJESH KUMAR SINGHAL
}

\begin{abstract}
SUMMARY
Drought is one of the major environmental constraints for the agriculture crop worldwide and overcome of yield penalty under drought situations, is the major goal for agriculturist in future. To achieve this goal, screenings of landraces is one of the most important genetic resources for crops improvement especially in dry areas. The present study was carried out during 2015-2016, in order to evaluate drought tolerance in eight fenugreek genotypes, under both control and drought conditions, various parameters were recorded at flowering and pod formation stage. The experiment was laid out in Randomized Block Design and replicated thrice. Physiological and biochemical parameters viz., plant height,relative water content (RWC), chlorophyll a, b and total chlorophyll content, carotenoids content, membrane stability index (MSI) and proline content were used to assess drought tolerance in fenugreek genotypes. Ranking of genotypes based on SY at both flowering and pod formation stage showed that Rmt-1 and Rmt-305 variety has the highest SY among the tested genotypes under control and drought condition. Among the observed parameters all parameters had positive correlations with SY except proline content and recommended for screening of susceptible and tolerant fenugreek genotypes for drought stress.
\end{abstract}

Key Words : Carotenoids, Drought, MSI, Proline, Relative water content, Seed yield (SY)

How to cite this article : Chauhan, Jyoti, Kakralya, Bajrang Lal and Singhal, Rajesh Kumar (2017). Evaluation of morphophysiological attributes of Fenugreek (Trigonella foenum graecum) genotypes under different water regimes. Internat. J. Plant Sci., 12 (2): 271-281, DOI: 10.15740/HAS/IJPS/12.2/271-281.

Article chronicle : Received : 21.04.2017; Revised : 08.06.2017; Accepted : 23.06.2017

MEMBERS OF THE RESEARCH FORUM

Author to be contacted :

JYOTI CHAUHAN, Department of Plant Physiology, Sri Karan

Narendra Agriculture University, JOBNER (RAJASTHAN) INDIA

Email : jc6173000@gmail.com

Address of the Co-authors:

BAJRANG LAL KAKRALYA, Department of Plant Physiology, Sri Karan Narendra Agriculture University, JOBNER (RAJASTHAN) INDIA

RAJESH KUMAR SINGHAL, Department of Plant Physiology, Institute of Agricultural Sciences, Banaras Hindu University, VARANASI (U.P.) INDIA 